\title{
Prevention of Financial Risk of PPP Mode Dong Yanmei
}

\author{
School of Economics, Yunan University of Finance and Economics, Kunming Yunnan,China \\ 79091354@qq.com
}

Keywords: Financial Risk, Public Private Partnership, Government Debt

\begin{abstract}
PPP is called "public private partnership" in China. With its rapid development, some have been generalized and abused, such as the project is not suitable for PPP, PPP legal system is not perfect and the model is not standardized, interests of government and social capital are inconsistent, the cooperation between both parties is "internalized", as well as the imperfect supervision system, which lead to the PPP project contains financial risk. In order to prevent it, precautions should include putting PPP into government purchasing, assessing projects scientifically, strengthening supervision and improving evaluation system.
\end{abstract}

\section{PPP模式的财政风险及防范}

\author{
董艳梅 \\ 云南财经大学经济学院, 昆明, 云南, 中国 \\ 79091354@qq.com
}

关键词：财政风险; PPP; 政府债务

中文摘要：中国称PPP为“政府与社会资本合作”。在其迅速发展的过程中，出现了一些泛化滥 用现象, 如项目不适宜使用PPP、PPP法律体系不完善和模式不规范、政府和社会资本利益导 向不一致、双方合作行为“内部化”、以及财政监管体系不完善等导致PPP项目蕴含较大的财政 风险。防范措施应包括, 将PPP纳入政府采购管理、科学评估项目、加强监管和完善绩效评 价体系，以推动PPP回归公共服务创新供给机制的本源。

\section{1. 引言}

我国引进 PPP 模式发展公共事业得到了快速发展，但为了进一步推进 PPP 规范发展，防 止 PPP 泛化滥用现象，财政部发文出台相关指导意见、规范项目库管理等政策通知，及时纠 正项目规范实施“难”、健全配套政策“难”、社会资本退出“难”、人才队伍建设“难”等问题，推 动 PPP 回归公共服务创新供给机制的本源, 促进实现公共服务提质增效目标, 夯实 PPP 可持 续发展的基础, 这对于防范财政风险具有保障性意义。

\section{2. 文献回顾及相关概念}

\subsection{PPP的概念}

PPP是“public private partnership”的缩写, 它的译法有好多种, 如公私伙伴关系、公私合 作伙伴模式、公私机构的伙伴合作、民间开放公共服务、公共民营合作制等等（贾康、孙洁， 2009）。[1]我国政府文件中称“政府和社会资本合作”。而关于其定义，不同的研究机构和研 
究者均有不同的表述。如联合国发展计划署、联合国培训研究院、欧盟委员会、美国PPP国 家委员会、加拿大PPP国家委员会对其的定义就不一样。不过却有着一些共同点, 即合作是 PPP的前提, 目标是提供公共产品或服务, 强调利益共享共赢和风险共担。在国内, 普遍的 学者已经认同, PPP是公共基础设施中的一种融资模式, 而且不仅是一种融资模式, 更是一 种管理模式，因为它不仅是政府得到了资金，而且是项目得到了公共服务，是一整套服务。 如孙洁 (2015) 认为PPP 是一个管理模式而非融资模式。PPP作为一种管理模式, 是指政府 公共部门与民营部门合作过程中，让非公共部门所掌握的资源参与提供公共产品和服务，从 而实现政府公共部门的职能并同时也为民营部门带来利益。[2]达霖.格里姆赛和莫文.K.刘易斯

（2008）也指出公众对PPP工程常有一种误解, 认为它们主要是私营部门为公共基础设施建 设融资, 而其实融资只是其中一个方面。 ${ }^{[3]} \mathrm{PPP}$ 的本质在于公共部门不再是购买一项资产, 而是按规定的条款和条件购买一整套服务（孙洁，2015）。[4]所以，PPP是公共基础设施中的 一种项目运作模式。在该模式下，鼓励私营企业、民营资本与政府进行合作，参与公共基础 设施的建设, 形成“利益共享、风险共担、全程合作”伙伴合作关系。PPP的优势在于使合作各 方达到比单独行动预期更为有利的结果，即政府的财政支出更少，企业的投资风险更轻。

\subsection{PPP与财政风险}

财政风险的反面是财政可持续性。财政可持续这个概念衡量国家财政存续状态和能力, 其中心是测量政府所面临的债务风险以及评价政府偿还债务的能力。现阶段大多数探讨PPP 的文献主要集中在实施和推广PPP项目（模式）的意义和积极作用, 认为PPP是公共基础设施 中的一种融资模式，在该模式下，鼓励社会资本与政府进行合作，参与公共基础设施建设。 在不增加财政风险的情况下, 推广PPP 项目可以缓解地方政府融资难的问题, 保持基础设施 建设的持续运作，对财政可持续性具有积极影响。

这些积极意义可归结为减少财政负担、利用社会资源、利用社会先进技术、机制创新、 合作共赢等。但开展 PPP 项目是否对财政可持续性存在影响, 或者说存在财政风险的文献却 很少, 只有黄芳娜、王悦（2016）等认为 PPP 模式蕴含的财政风险主要是两方面, 一方面是 政府盲目投资 PPP 项目带来的投资过剩, 另一方面是 PPP 法律不完善或监管不到位带来的财 政投资损失。 ${ }^{[5]}$ 本文将系统梳理这方面的研究, 并在此基础上提出防范 PPP 模式蕴含的财政 风险的措施。

\section{PPP模式蕴含的财政风险}

长期以来，我国公共服务基本都是由政府提供的，因此，从既有的传统供给模式转向政 府与社会资本共同提供, 难免会存在一些问题, 比如参与主体的利益不一致的矛盾、政府投 资 PPP 项目具有盲目性、PPP 合作程序不规范、监督管理不够, 缺乏 PPP 完整的法律保障体 系等, 这些问题的存在一方面会影响公共产品和服务的提供和质量, 同时也在较大程度上增 加了财政风险。这些风险有:

\section{1 政府和社会资本利益导向不一致蕴含的财政风险}

政府部门投资PPP主要是解决公共产品和服务的提供不足的困境, 它代表公众追求的是 公平, 公众希望得到更多物美价廉的公共产品和服务, 所以政府部门的目标并不是利润最大 化。而社会资本却不一样, 本着资本逐利的属性, 它追求的是高效率和高收益, 或者说是希 望追求利润最大化的。总之, 各方利益的诉求是不一样的, 但作为参与PPP项目的资本, 却 必须遵循任何PPP项目都是公益性项目, 不以利润最大化为目的。[1]所以, 政府部门与社会资 本的目标利益的差异，会导致财政风险的产生。

其次协调各方利益是一件复杂的事情。一方面，从地方政府、社会资本、金融机构各方 反映的情况看, PPP项目的顺利实施, 与配套政策是否健全密切相关。目前, 土地、价格、 
融资等方面的配套政策，亟需进一步完善。然而，这些政策涉及面广、协调难度大，短期内 出台存在一定难度。另一方面, 政府资本和社会资本合作的边界是一片区域, 而非明确的界 限，所以可能会导致合作过程中的双方责任模糊区，双方责任模糊带来了政府投资的低效率; 对政府部门而言, 这种责任边界的模糊区往往是官员“道德风险”的高发区, 蕴含较高的财政 风险。

\section{2 项目不适宜使用PPP模式蕴含的财政风险}

在政府大力推广PPP模式的宏观大背景下，PPP模式的“双赢”优势不仅吸引了地方政府大 力上马项目, 也博得了社会资本的青睐, 但实际上并非所有的公共服务项目都适合通过PPP 模式来运营。比如, 因涉及国家安全或重大公共利益等的项目, 就不适宜由社会资本承担; 仅涉及工程建设, 无运营内容的项目也属于不适宜采用PPP模式实施的情形。而不属于公共 服务领域，如商业地产开发、招商引资项目等项目，因政府不负有提供义务，就更不适宜使 用PPP模式了。除此之外，财政部财办金[2017]92号文《关于规范政府与社会资本合作（PPP） 综合信息平台项目库管理的通知》中列举了不符合新项目入库标准的情形, 因为这些情形的 存在, 增加了政府债务的风险, 蕴含着较大的财政风险。

\subsection{PPP法律体系不完善或模式不规范蕴含的财政风险}

在中国，PPP作为一种新生事物，在逐渐清晰、明确定位的过程中，难免出现交叉、多 头管理现象, 众多规章政策指令对于PPP模式形成的矩阵型约束虽致力于使其发展得更加规 范, 但缺乏较高层次和统一的法律层面的硬约束, 使得PPP模式蕴含较大的风险。除此之外, 在PPP项目实施过程中, 存在一些管理不规范的行为, 财政部在《关于规范政府与社会资本 合作 (PPP) 综合信息平台项目库管理的通知》中明确指出这些不规范行为都会增加财政风 险。

\section{4 政府和社会资本合作行为“内部化”蕴含的财政风险}

社会组织在政府和社会资本合作中起着很重要的作用, 但有时它会成为政府部门的延伸, 失去自主性，带来服务质量、费用合理性以及资金透明度等问题，蕴含较大的财政风险。

一般情况下, 在PPP过程中,有些项目会以原来的组织机构为基础不再设立新的组织机构, 而有时会因特殊的项目而设立新的组织机构, 是为社会组织, 人员一般会由公共部门和民营 部门双方共同组成, 根据合同要求安排相应的管理职位。这些机构虽为社会组织, 但是在政 府有特定购买需求后产生的, 是由有购买需求的地方政府主导成立的。从实际运作结果看, 这些社会组织是与政府行政性质相同的“次级政府”，他们之间在实际运行中缺乏强有力的契 约关系。在已有的案例中, 这些社会组织名义上承接政府委托的公共事务, 实际上是接受政 府下派的任务, 而非独立于购买主体, 即地方政府之外的法人主体, 这种情况导致购买公共 服务的行为“内部化”，势必偏离PPP模式可充分利用社会资本优势的初衷。

\section{5 财政监管管理体系中的财政风险}

在 PPP 模式中，社会资本和地方政府的利益导向不一致，会产生一定的合作风险，尤其 是在政府监管不到位的情况下，比如说，社会资本在经济利益目标下会出于节省资金成本而 降低服务质量, 而地方政府在社会效益目标下为了迎合居民而盲目上规模。这种矛盾在我国 尚缺乏统一的 PPP 实施细则下, 体现出操作性差, 无法对 PPP 过程的市场准入、特许经营制 度、运行安全、产品与服务质量、价格与收费、成本等具体方面进行监管。

而且，在我国政府监督管理中，突出表现为上级监督管理严于下级监督管理，即存在着 国家层面监管严于省级层面监管, 省级层面监管又严于市级层面监管, 市级层面监管又严于 县级监管的特点（王振宇，2010）。[6]导致地方政府对监管也只是做出笼统的规定，并未涉 及到在监管过程中责任的分担及相应的法律后果。 
特别是，PPP 项目监管中缺乏专门的管理人才也直接导致了财政风险的存在。PPP 在我 国的开展时间没有国外长, 政府对这类人才培育的起步也比较晚, 目前尚缺少既熟悉该领域 规范操作、懂得行业标准和成本核算, 并可开展绩效评价的复合型人才。这不仅使得政府无 力有效监管，同时也无法借助中介评价机构对财政支出效率或 PPP 项目作出合理评价。

\section{4. 防范建议}

本着 PPP 项目是公益事业, 财政支出必须遵循“预算编制有目标、预算执行有监控、预算 完成有评价、评价结果有反馈、反馈结果有应用”的原则, 防止财政风险的产生, 提高 PPP 项目的效率，具体可采取的措施有:

\section{1 纳入政府采购管理}

多部门管理和领导 PPP 项目, 带来管理的混乱和低效率。目前学界已基本取得共识，虽 PPP 项目不属于传统意义上的政府采购, 但就 PPP 项目与政府采购的关系而言, 是可以将其 归入政府采购的。 ${ }^{[7]} 2014$ 年 12 月 31 日, 财政部正式发布《政府和社会资本合作项目政府 采购管理办法》，以推广 PPP 模式, 规范 PPP 项目政府采购行为。2015 年 2 月 25 日, 财 政部在官方网站发布了《2015 年政府采购工作要点》, 其中阐明的八个工作要点之二, 就是 在大力推进政府购买服务等各项改革工作中力推将 PPP 项目纳入政府采购管理工作。

PPP 项目纳入政府采购管理的意义首先体现在，因为政府采购使用的是财政预算内资金， 所以 PPP 项目纳入政府采购管理之后, 在预算层面就从制度上保障了部分具有运行缺口的项 目补贴; 其次, 将 PPP 项目纳入政府采购管理之后, 其运行管理势必需要遵循政府采购相关 法律法规和政策规章等约束，相关矩阵型政策规章也将以政府采购法等法律层面的硬约束为 基础全部理顺，将 PPP 项目推向更加规范的运行层面。

\section{2 科学评估PPP项目}

我国规定 PPP 项目必须经过“物有所值”评估，即 VFM 评估。VFM 是 Value for Money 的 缩写, 一般译为“物有所值”。这一概念主要源于 20 世纪 90 年代的英国。英国审计署把它定 义为“最优化利用可用资源以获取想要的结果”, 包含三个方面, 即节约（Economy）、效率 （Efficiency）、效果（Effectiveness）。PPP 模式下的物有所值主要是一个相对概念, 需要将 PPP 模式与政府传统采购模式进行比较。假设两种模式的效果相同, 则比较投入的多少就可 以判断哪种模式更能实现物有所值; 如果假设两种采购模式的投入相同, 则比较所获效果的 好坏就可以判断哪种模式更物有所值。

没有经过这一评估过程的项目，使得投资过多过滥，缺乏效率，无法了解效果，加大了 政府的投资性支出，财政负担就会加重，不利于财政可持续性。

\section{3 加强PPP项目的监管}

强化项目的全生命周期监管, 首先要实行公开招标, 好处是不需要通过谈判, 就可以实 现收费年限和投资回报率等主要问题的最佳结果。公开招标的公正性还有利于提高效率, 防 止腐败, 并利于研究, 总结和交流推广经验, 包括对相关官员进行培训, 进行能力建设, 以 实现知识管理，不断优化和改进 PPP 模式的应用。

其次要公开透明，这是监管的基础。在招标和评标过程中，政府公开有效信息，让公众 了解自己所享受到的公共产品或服务的成本是多少，尤其是社会资本的预算，利于公众和独 立第三方咨询机构等其它各方参与, 提供合理化建议, 完善决策过程, 也利于避免黑箱操作, 预防腐败。在项目建设和运营过程中，公开信息则有利于社会监督和激励企业控制成本、提 高效率，提高服务水平，保障政府和公众利益，提高后续类似项目的决策和管理水平，等等。 最终形成过程监督、质量监督和成本监督的全过程监管。 


\section{4 完善绩效评价体系}

PPP 项目中政府资本属于财政支出, 所以应纳入财政支出绩效考核的范畴, 但 PPP 项目 建设运营又有一定的特殊性, 所以, 应在现有财政部门绩效评价制度的基础上, 建立一套独 立、完整的 PPP 项目建设运营绩效评价体系, 将绩效评价程序规范化, 设立专门的机构对 PPP 项目的实施情况进行跟踪评价, 对评价结果依法对外公开, 接受社会监督, 鼓励公众参 与对项目的监督, 切实提高项目实施水平和效益。并将绩效评价结果作为 PPP 项目的财政补 贴、收费标准、合作期限等重要内容调整的依据, 可通过合同约定具体调整条件和方式, 保 证公共利益最大化。 ${ }^{[8]}$ 比如说, 对于获得特许经营权的企业, 规定其应至少两年进行一次经 营情况的中期评估，等等。

\section{References}

[1] K.Jia and J.Sun, Characteristics and functions of PPP mode, Economic Review, vol.8, pp.7-10, 2009.

[2] J.Sun,PPP is also a mode of management, Construction Enterprise Management, vol.4, pp.25-26, 2015.

[3] D. Grimsey and M. W. .K Lewis, Public-private partnership: a global revolution in infrastructure supply and project financing, Beijing: China Renmin University press, 2008.

[4] J.Sun, PPP from the perspective of management: characteristics, components and basic principles. Research on Local Finance, vol.8, pp. 4-14, 2015.

[5] F.N. Huang and Y.Wang, Impact of PPP model on fiscal sustainability. China Collective Economy, vol.1, pp. 86-87, 2016.

[6] Z.Y. Wang, A study on the "dilemma" of local financial growth and sustainable development . Finance Research Bulletin (internal research report), vol.36, 2010.

[7] J. Sun and J.CH.Su, Significance of integrating PPP projects into government procurement management . Government Procurement, vol.3, 2016 .

[8] L.CH.Wen and Y.Y. Guo, Research on government budget management of PPP projects. Reference for Economic Research, vol.31, pp. 38-44, 2016. 